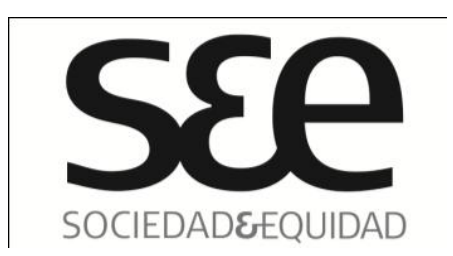

SOCIEDADEEQUIDAD

\section{Desarrollo, subjetividad y transgresiones identitarias en las costas del sur-austral chileno $(*)$}

\author{
Nombre: Gonzalo Saavedra Gallo (**) \\ Universidad: Universidad de Los Lagos \\ Ciudad: Osorno \\ País: $\quad$ Chile \\ Correo: $\quad$ gonzalosaavedragallo@gmail.com
}

\title{
Resumen
}

Este trabajo se enmarca en una investigación sobre las dinámicas contemporáneas del desarrollo y la modernización en las costas sur-australes de Chile, específicamente en el litoral norte de la región de Aisén. A partir de un conjunto de datos etnográficos se propone una reflexión teórico-conceptual que permita problematizar e interpretar esos datos en función de una lectura política y, por qué no decirlo, transformadora del mundo costero sur-austral. El argumento central del texto tiene carácter hipotético: las encrucijadas del desarrollo, en las actuales coyunturas de las costas aiseninas, son susceptibles de ser resueltas (al menos hasta cierto punto) a partir de un giro reflexivo y consciente sobre eso que en antropología llamamos cultura.

\section{Palabras claves}

Pesca artesanal, costa sur-austral, subjetividad, reflexividad, Chile.

\footnotetext{
( ) Una versión inicial de este trabajo fue presentada en el VI Congreso chileno de antropología, "Miradas desde el sur" Valdivia, 13-17 de Noviembre 2007.

(**)El autor es Doctor en Ciencias Políticas y Sociología e investigador del Centro de Estudios del Desarrollo Regional y Local, Universidad de Los Lagos. Entre sus principales intereses destacan los procesos de modernización y desarrollo en economías pesquero-artesanales, las dinámicas de expansión capitalista en espacios rurales, y los sistemas agroalimentarios localizados.
} 


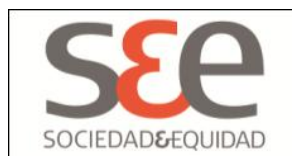

\section{Development, subjectivity and identity transgressions in coast of southern Chile}

This work is part of an investigation into the contemporary dynamics of development and modernization in the southern and far southern coastal areas of Chile, specifically the shoreline of the northern part of the Aysen Region. The objective is to propose a theoretical-conceptual reflection to enable ethnographic data to be framed as a problem and interpreted as a function of a political reading which - why not say so? - could transform the world of the southern and far southern coastal zone. The central argument of the text is hypothetical: the dilemmas of development, in the current circumstances of the coasts of the Aysen Region, are susceptible of resolution (at least up to a point) from a conscious, reflexive change of perspective on culture as the word is understood in anthropology.

\section{Keywords}

Artisanal fish, southern coastal, subjectivity, reflexivity, Chile 


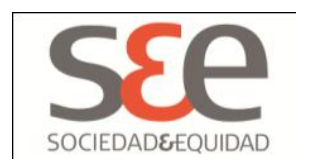

\section{Introducción}

Ante un escenario de transformaciones territoriales, económicas y socioculturales, vinculadas principalmente a la expansión -y posterior crisis- de la industria productora de salmones en cautiverio por las costas del sur-austral chileno, y en particular aiseninas, cabe formularse las siguientes interrogantes: ¿Cuáles son las perspectivas de reformulación del desarrollo a partir de las cualidades subjetivas de las comunidades costeras del Archipiélago de los Chonos?, ¿Es posible que la reinvención local del desarrollo, en ese contexto, ocurra desde los atributos culturales de las comunidades en cuestión? Las interrogantes exigen simultáneamente una interpelación crítica a la noción de desarrollo, ampliamente debatida en las ciencias sociales y particularmente en la economía; asimismo demanda la problematización de la propia noción de cultura, quizá más intrincada aun -y políticamente recurrida- en las encrucijadas desarrollistas. Esta última problematización conlleva además una interrogante acerca del lugar de las dinámicas identitarias, locales y localizadas, que se despliegan en este complejo y conflictivo escenario. Lo anterior se explica, en tanto la invocación de los atributos y las cualidades culturales locales comporta el riesgo de asumir posiciones primordialistas y estáticas, altamente incómodas si se trata de investigar procesos que entrañan flujos y transformaciones permanentes.

Este trabajo es reflejo de una investigación que combina reflexiones conceptuales y experiencias de campo. Lo que hay aquí es una contrastación de lo conceptual a partir de una dimensión etnográfica, cuya hipótesis señala que lo cultural supone una dimensión subjetiva poco recurrida, e incluso desestimada desde las posiciones positivistas y/o racionalistas tan asentadas en el pensamiento social, pero que sin embargo es potencia transformadora de sí misma. Entre los años 2003 y 2007 realicé sucesivas estancias de trabajo de campo en el litoral austral -Chiloé y Aisén- entre las que sobresalen las expediciones de enero 2003, octubre 2004, junio 2006 y mayo 2007. En este contexto se construyen las principales observaciones que me permiten sostener que sí es posible una reformulación político-cultural del "desarrollo" (o del proceso de "modernización") y que ese proceso ocurre precisamente a partir de esa dimensión política -y reflexiva- de la vida cultural y económico-cultural.

\section{Escenarios de transformación en el sur-austral: problematizando el desarrollo}

De forma sintética, sin entrar todavía en la cuestión teórica, me interesa señalar que utilizaré una fórmula específica para relativizar el desarrollo, si cabe decirlo, una hipótesis. Esta fórmula es más o menos la siguiente: tanto la crítica como la deconstrucción del desarrollo -como proyecto de inspiración occidental- son ejercicios limitados, de corto alcance político, en tanto no conlleven un proceso subjetivo e intersubjetivo de transgresión de sus fronteras estructurales. La potencia de esa transgresión se instala en la subjetividad (de los actores localizados) y fluye en esa subjetividad como pensamiento consciente capaz de reimaginar - y transformar- las condiciones del presente proyectadas hacia un futuro mejor. 


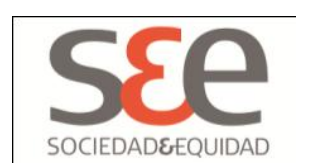

Mi trabajo de campo se focalizó sobre todo en lo que he denominado el eje bentónico ${ }^{1}$ de la costa sur-austral de Chile, específicamente en las Islas Guaitecas y en las Islas Huichas. El carácter de este trabajo fue etnográfico en el sentido de la experiencia del viaje, del lugar, del registro y especialmente en el sentido de la opción teórico-conceptual que he utilizado. En principio mis reflexiones y aproximaciones al problema del desarrollo en las sociedades locales, estuvieron muy marcadas por experiencias anteriores. Entre 1998 y 2002 trabajé en el litoral aisenino e incluso residí dos años en Puerto Melinka (comuna de Guaitecas), todo ello en el marco de un programa de superación de la pobreza en comunidades rurales. El enfoque de esa intervención, aun concebida en lo local y en el abajo, estaba condicionada por la matriz convencional del desarrollo. Implícita y explícitamente nos sentíamos portadores de certezas, claridades, fórmulas y soluciones. Sentíamos que nuestra misión era transmitir esas certezas e instalar esas soluciones. Posiblemente, en lo más profundo de la concepción del otro y en su matriz epistemológica, estas prácticas y discursos del desarrollo -muy arraigadas en la praxis político institucional- no difieran demasiado de aquella que ha impulsado la gran transformación salmonera. En uno y en otro caso somos nosotros, los expertos, quienes podemos explicar o incluso "comprender" las condiciones culturales locales, y según eso somos nosotros quienes diseñamos las "intervenciones" y decidimos qué ha de hacerse.

El paisaje que observé en las islas Guaitecas y desde las islas Guiatecas (hacia Aisén y hacia Chiloé), era el de un espacio económico y cultural inmerso en un proceso de cambio. Ese cambio era visible -y estaba en gran medida ya realizado- en Chiloé y a partir de ello era imaginable en el litoral aisenino. En clave modernizante se podía ser testigo de la transición de los sistemas pesquero-artesanales tradicionales a unas economías formalizadas y precarizadas por los influjos de la industria. En el caso de Guaitecas la base de pesca artesanal bentónica, de matriz chilotahuilliche, era marcada. En 1998 el devenir de la vida cotidiana seguía muy condicionada por los ciclos anuales de las pesquerías que por entonces, directa e indirectamente, ocupaban a la mayor parte de la población: extracción de erizos, de almejas, y de algunas algas con cierta importancia comercial. Un día típico en Puerto Melinka se iniciaba muy temprano en los distintos embarcaderos artesanales del pueblo; el arcaico ruido de los motores centrados -característicos de los modestos botes bentónicos- inundaba poco a poco la tranquila atmósfera de los días. Entonces era posible ver a los hombres (porque en la práctica sólo hombres ejercían el oficio de buzo mariscador), en cuadrillas de tres o cuatro integrantes, salir o regresar de las faenas. Las faenas podían durar hasta tres semanas y de forma tácita congregaban a muchas embarcaciones en un mismo sector del Archipiélago, incluso algunas provenientes de puertos tan distantes como Quellón o Calbuco. Distancia geográfica pero no cultural, por cierto.

La siguiente imagen me fue relatada en octubre de 2006. Le pedí a un buzo que por entonces debía tener unos 35 años, y a quien llamaré Manuel, que me describiera cómo eran las faenas. Su

\footnotetext{
${ }^{1}$ El Bentos refiere al grupo de organismos que, en forma permanente o semipermanente, se encuentran asociados al fondo marino, sobre él o semienterrados. Las economías bentónicas son aquellas que basan sus dinámicas de reproducción material en la extracción de estos recursos.
} 


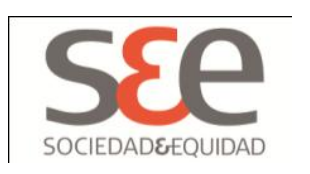

relato es extenso, de finos y coloridos detalles, no obstante reseñaré lo que a mi juicio permite captar lo esencial de esa instancia que articula la vida económica de la pesca artesanal local:

En la tarde se busca un buen puerto de acuerdo al viento que corra, previniendo cualquier tempestad que pueda desatarse en la noche y todas las embarcaciones se juntan, hacen como una población flotante y todos tiran sus buenas anclas, ya sea a la proa o a la popa para que en la noche puedan dormir tranquilos, pegadas. Atracadas una al lado de otra, y ahí uno después que hace todas sus labores, generalmente sale a pasear a otra lancha o le llegan visitas a la de uno. Porque ha andado todo el día con los compañeros, ¿ंierto?, necesita conversar con otra persona o tiene un amigo, o va a jugar a las cartas o al truco, o a la brisca... cuando se va a jugar al truco o la brisca, se fuma mucho, y se cuentan muchas mentiras entre todo el juego. $Y$ bueno, llega el momento en que se comienza a acostar un bote, se acuesta uno y comienzan a acostarse todos. Es como un orden que tienen, porque obviamente si alguien quiere descansar, el resto tiene que respetar el descanso y no meter bulla, para eso mejor descansar todos juntos. Al otro día, se levanta el primero, y se levantan todos enseguida.

Generalmente las faenas son de diez a doce botes, y como tú sabes las embarcaciones son chiquititas, constan de tres camarotes; siempre van dos camarotes al lado de la cabina y uno al otro; y dónde va el camarote que está solo, en una esquina va la cocina, y alrededor de la cocina están todos los utensilios que se necesitan... Así que tienes que andar con tus cosas bien ordenaditas porque el espacio es muy reducido. Generalmente la convivencia es buena, es muy buena, porque ya está todo tan mentalizado [que] el trabajador para ir anda con una voluntad muy buena. Generalmente dura entre veinte y veinticinco días ${ }^{2}$.

En la actualidad las cosas han cambiado, de hecho el testimonio de Manuel se enmarcaba en esa perspectiva. En particular, en la situación de la pesca artesanal respecto de la expansión de los centros de cultivo por el borde costero aisenino. En 2006 y en 2007 aún reinaba el optimismo algo desmesurado- entre los industriales, quienes vaticinaban que la producción chilena estaba muy cerca de superar a la noruega en el primer lugar a nivel mundial. En cualquier caso es un relato representativo, aun cuando ya en esos años muchos buzos locales habían cambiado la faena por el empleo en los centros de cultivo. Sólo la crisis financiera mundial y sobre todo la

\footnotetext{
${ }^{2}$ Entrevista realizada en octubre 2006, Puerto Melinka.
} 


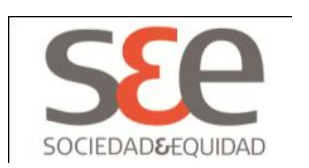

crisis sanitaria del virus ISA, que calaría hondo en 2008 y 2009, vino detener en parte el flujo de buzos hacia la industria.

En mayo de 2007 realicé mi último viaje a las islas Guaitecas, entonces registré todo el itinerario en notas de campo que luego sistematizaría como dato empírico. Comparto aquí mi propio testimonio, pues de alguna forma grafica el contraste entre esos dos momentos de la vida económica local y, creo, evidencia el impacto de la transformación salmonera.

En 1998 Chiloé era un paisaje a medio camino entre varias cosas: semirrural, semicostero, semiempresarial, semicampesino, semipesquero-artesanal, etcétera... pero ahora, casi diez años más tarde, es un lugar que podríamos denominar híbrido, pero si bien es esa hibridez donde todo parece aglutinado en lo mismo, en el mismo espacio, por otro lado queda siempre la sensación de contrastes de inequidad, de mundos distintos y distantes cohabitando en la vecindad bucólica de los canales. El fragmento es probablemente mejor metáfora que la unidad. Es una buena referencia para pensar ahora en Melinka: la vida salmonera ha sabido estar en el pueblo, ha encontrado su lugar, ha creado su propio barrio de lujo, ha instalado sus arquitecturas, sus servicios de electricidad y agua potable, pero aunque esté tan cerca no es posible ver a ese mundo integrado en el otro, es como que ahora más que antes hay dos Melinka, el de siempre, el de los melinkanos y las melinkanas, y el Melinka sofisticado y provisorio de los salmoneros.

Evidentemente no hay una frontera tan mecánica entre uno y otro mundo, sin lugar a dudas hay vasos comunicantes, parte del uno y del otro se entremezclan y dan origen a algo nuevo, a algo que no estaba... en eso consiste otra variante, quizá la más interesante pero a la vez compleja, de la transformación. Se generan nuevas identidades de vida social, pero también de vida económica ${ }^{3}$.

\section{La modernización salmonera}

El proyecto modernizador salmonero ha implicado diversas cuestiones en las costas de Chiloé y Aisén. En el plano de sus consecuencias cabe destacar impactos ambientales y territoriales, socioeconómicos, socioculturales y políticos. Entre los de tipo ambiental-territorial se pueden reseñar los severos deterioros en el ecosistema marino y la progresiva privatización de vastas zonas del borde costero. A nivel socioeconómico se constatan variaciones relevantes en los sistemas de trabajo y en los tipos de fuentes laborales. En el plano sociocultural se evidencian procesos de reformulación identitaria y de prácticas cotidianas. Por último a nivel político,

\footnotetext{
${ }^{3}$ Registro etnográfico, 20/05/2007, Puerto Melinka.
} 


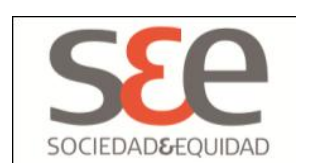

vinculado al proceso de transformación, se han activado tímidamente algunas dinámicas organizacionales y otras demandas colectivas al interior de las comunidades (y también fuera de ellas).

A mediados de los años noventa el cultivo de salmones en el sur de Chile era un negocio más que prometedor, con una prosperidad tal que prácticamente la totalidad del borde costero interior de la isla de Chiloé y gran parte del estuario de Reloncaví (en el entorno de Puerto Montt), estaban saturados de centros de engorda. Ante perspectivas tan favorables, fue necesario proyectar una segunda fase expansiva, y es así como hacia 1997 comienzan a proliferar las jaulas de cultivo en los canales y fiordos australes, principalmente en zonas aledañas a las islas Guaitecas, Puerto Cisnes y especialmente a Puerto Aisén (es decir, indistintamente en ambos ejes del litoral). La promulgación de la Ley de Pesca y Acuicultura en 1991 constituyó un instrumento de gestión administrativa fundamental en este sentido, pues entregaría toda clase de facilidades y garantías a los futuros inversionistas que quisieran extender sus negocios por la zona austral. Por ejemplo entre 1990 y 2000 las exportaciones netas de salmón cultivado se multiplicarían por cinco, pasando de 26.000 a 271.500 toneladas (CORFO 2002), para llegar en 2005 a las 383.700 toneladas (Salmonoticias, 15/02/2006). Después de Noruega, Chile había sido, entre 1995 y 2008, el segundo productor mundial de salmones y su objetivo a mediano plazo era convertirse en el primero. Al menos ese era el discurso predominante antes de la crisis desencadenada por la proliferación del virus ISA hacia fines de 2007.

Ahora bien, en la actualidad no resulta fácil presagiar qué sucederá con esta tendencia expansiva. Hoy en día las costas aiseninas continúan ofreciendo una excelente rentabilidad para el negocio salmonero a nivel mundial, la pregunta es en qué medida y cómo esta situación afecta y afectará a las localidades y a las economías costeras. En el momento más próspero de la industria una parte significativa de los buzos mariscadores se emplearon en los centros de cultivo, sin embargo, dadas las coyunturas referidas, el escenario ahora es incierto, no siendo posible aseverar que la pesca artesanal en la zona austral continuará mutando hacia la precariedad laboral salmonera. Pero tampoco se trata de suponer que todo volverá a ser como antes, en realidad la magnitud del fenómeno expansivo impele a pensar que la demanda industrial-extractiva por los recursos costeros seguirá siendo una condición de este espacio económico. Salmones más, salmones menos; al margen de las coyunturas, este tipo de transformaciones modernizantes suponen hitos que marcan el tránsito de una época a otra.

En uno o en otro escenario -crisis o prosperidad- la coyuntura reseñada expresa, desgraciadamente, las constricciones más destructivas de la expansión capitalista, socavando entre otras cosas la base material sobre la que se reproducen las economías en cuestión: el borde costero. Este proceso, para el caso análogo de Chiloé y el entorno de Puerto Montt, ha sido reseñado y documentado por ONGs ambientalistas y por algunos académicos especialistas en el tema (Claude y Oporto 2000; Doren y Gabella 2001; Pizarro y Zolezzi 2003; Buschmann y Fortt 2005; Kremerman, 2005; Durán et al 2007). 


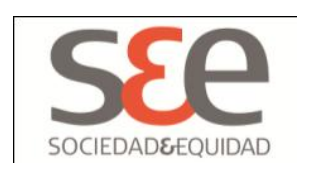

Cabe remarcar en este punto que, como sucede en todas las zonas rurales abundantes en recursos naturales de interés comercial, las dinámicas de transformación social constituyen tendencias históricas muy evidentes. De hecho, en el caso de las costas del sur-austral, la expansión de la salmonicultura es solo la última expresión de procesos asociados a la explotación de los recursos marinos y forestales que se remontan a tiempos coloniales. En este contexto, las preguntas que propongo no tienen que ver con las dinámicas estructurales, sino con las respuestas o las perspectivas político-culturales que, desde la dimensión subjetiva e intersubjetiva, permiten una problematización más sugerente del escenario en cuestión.

Lo que moviliza a los actores locales en las costas sur-australes

Sin entrar en un determinismo respecto de la economía, al menos en este caso, convengamos en que se articula sobre esa base de recursos naturales; es decir, las sociedades costeras de los archipiélagos aiseninos existen a partir del uso productivo que dan a ese espacio material. Cada vez que estuve en el litoral, y en particular en las islas Guaitecas, no dejé de preguntarme por qué ante la evidencia de un desarrollo destructivo la comunidad de actores locales -por ejemplo, los pescadores artesanales- no se movilizaban en consonancia con los impactos en su capital natural. En general desde fines de la década de 1990, cuando se iniciaba la expansión de centros productores de salmón por las costas de Aisén, el tenor de las movilizaciones de pescadores artesanales no ha dicho relación con la problemática en cuestión, sino más bien con las restricciones en las cuotas de captura y con las tensiones de zona contigua (que limita el acceso que históricamente tuvieron los pescadores de Chiloé a las costas aiseninas). Lo anterior no deja de ser llamativo en la medida en que se trata del sustrato material de estas economías, de esas culturas.

Tales preguntas, concretas y tal vez de sentido común, son las que dan origen a la problematización que a continuación espero sintetizar considerando algunas aportaciones teórico-conceptuales; pero que sobre todo me interesa utilizar como punto de partida para demostrar que sí es posible repensar -literalmente- el desarrollo en el sur-austral de Chile desde esa dimensión intersubjetiva que he denominado político-cultural.

\section{Estructura, límites y transgresiones del desarrollo}

Las perspectivas antropológicas sobre el objeto cultural han estado marcadas por la lógica de la estructura. De distintos modos, se ha concebido que los acontecimientos están condicionados y constreñidos por factores que escapan a las subjetividades y a las voluntades, individuales y colectivas, implicadas en ellos. Marshall Sahlins (1988), siguiendo los postulados de Lévi-Stauss, dirá que las temperaturas estructurales pueden ser frías o calientes. Aquellas con temperaturas frías son más estables y tienden a permanecer en el marco de las coyunturas, mientras que aquellas con temperaturas calientes son más susceptibles de transformarse en las encrucijadas de lo inesperado. Al primer tipo le denomina prescriptiva y ejerce un pesado efecto de condicionamiento, al segundo tipo le denomina performativa y su efecto es el inverso: el dinamismo, el cambio. Sin embargo, no necesariamente la resignificación o la revalorización 


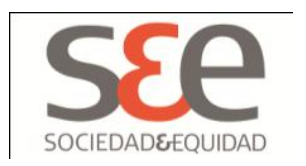

funcional de la estructura, implica una acción deliberada sobre la misma, pues esta dinámica es una condición propia de lo cultural.

Esta tensión -estructura / subjetividad- también ha sido abordada de forma sugerente por Arjun Appadurai (2001). El autor ha fijado su atención en la imaginación, según él, una variable desestimada en la teoría antropológica. Lo cultural no implica "simplemente la posesión de ciertos atributos... sino también la consciencia de tales atributos...", por ello "...la idea de etnicidad aquí propuesta tiene por núcleo la construcción y movilización consciente e imaginativa de las diferencias" (Appadurai, 2001: 29). Appadurai reabre la perspectiva de lo consciente, de esas facultades creativas e imaginativas que también existen en la vida cultural. Pero no reduce la imaginación a una propiedad individual, tal como se ha concebido con frecuencia en Occidente, sino que la entiende como atributo del colectivo, y en ese sentido le asigna un valor transformador, identitariamente dinámico. La imaginación es potencialmente subversiva de sus propios límites y, si se piensa en ella como condición social, podrá observarse que esos límites son los de su espacio cultural.

Esta crítica ya era sugerente en los enfoques que relativizaron la autoría en la investigación etnográfica. Un caso precursor fue el trabajo de Paul Rabinow (1992) en Marruecos, relato retrospectivo de un itinerario iniciado en 1968 cuyas principales características son la translocalidad ${ }^{4}$, el viaje y la dialógica reflexiva. Se superan aquí algunas convenciones respecto del objeto antropológico. En primer lugar, se entiende que ya no es posible situarse en un espacio local sin problematizar su contexto y sus condicionamientos globales. En segundo lugar, hay una ruptura aun más decisiva en el plano metodológico: el trabajo de campo como diálogo entre el etnógrafo y sus informantes, siendo estos últimos actores pensantes (intérpretes conscientes) de su propia condición cultural y política. Se está aquí muy lejos del paradigma malinowskiano, en donde los otros constituyen subjetividades tipo, pensadas y explicadas desde la experticia académica. Lo que cabe concluir del trabajo de Rabinow es que nuestros informantes -esos otros del desarrollo- son política y reflexivamente activos.

En el ámbito del desarrollo, la subversión respecto de las dinámicas estructurales - sobre las identidades y desde las identidades- abre perspectivas que enriquecen el papel de la subjetividad en la construcción y reconstrucción del espacio cultural. Como escribió García Canclini (1990), en América Latina el desarrollo moderno no necesariamente suprime las culturas tradicionales, por el contrario, éstas se desarrollan transformándose. Lo tradicional-local, cree el autor, no es vivido por los sujetos como complacencia melancólica de tradiciones, más bien hay un proceso de resignificación-reelaboración de objetos y sentidos locales en donde campesinos, indígenas y otros actores del espacio localizado terminan creando "estrategias de prosperidad" sin dejar de sentirse y vivir como tales.

4 Un concepto que más tarde trabajaría magistralmente el propio Clifford, en sus Itinerarios Transculturales (1997). 


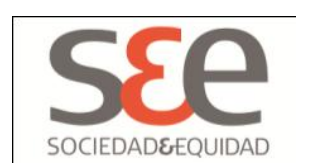

Sin embargo, esa prosperidad pareciera estar relacionada con cierto control sobre algunos elementos básicos de la reproducción cultural. Por ejemplo el control sobre el comercio y "el control más o menos igualitario sobre sus fuentes de subsistencia...", de hecho en la mayor parte de los casos "los datos son deplorables" y "no hay una adaptación exitosa al desarrollo capitalista" (ibíd., pp. 220-221). Entonces, si bien híbrida, heterodoxa y optimista, su visión sobre una versatilidad cultural, capaz de adaptarse a las condiciones de la modernización económica, no es una visión ingenua. Se trata de pensar que las sociedades "tradicionales" poseen un potencial de reelaboración del desarrollo modernizador. No obstante es una cuestión compleja, pues las dimensiones subjetivas del desarrollo no siempre se ajustan a estos modelos. Ahora bien, tampoco sobra insistir en que las lógicas culturales del capitalismo (como el espíritu emprendedor o la competitividad) también forman parte de los modelos económicos locales.

En un contexto similar, D. Barkin y M. Rosas (2006) proponen el concepto de "Actividades No Proletarias Generadoras de Ingresos (ANGI)". Bajo esa nomenclatura aluden a economías de matriz comunitaria, basadas en la confianza, articuladas en un manejo consciente de los recursos naturales, y que además son capaces de producir para interactuar con las lógicas de capitalismo. En la práctica suponen estrategias que posicionan a las comunidades en el mercado pero sobre la base de "valores, normas y principios ambientalistas". Coincidente es también la visión de A. Escobar (1999) y L. Grueso (2005), en sus estudios sobre el Proceso de las Comunidades Negras del Pacífico colombiano (PCN). En ambos casos se destaca la activación de un movimiento político-cultural o culturalmente consciente, que surge para defender modos de vida alternativos y economías locales no-capitalistas.

\section{Desarrollo, subjetividad y pensamiento local}

El posdesarrollo (Escobar 1997; Viola 2000; Esteva 2000), sostiene que existe en lo local una potencia de reformulación, de resignificación, incluso de resistencia próspera frente a la expansión del desarrollo modernizante, he ahí que en el inicio de este trabajo las preguntas aludiesen a las perspectivas de reformulación del desarrollo a partir de las cualidades subjetivas de las comunidades costeras de Aisén, o bien si acaso era posible que su reinvención local ocurriera desde los atributos culturales locales. Los enfoques convencionales han sido potentes en términos descriptivos y explicativos pero escasamente fructíferos en cuanto a las dinámicas de transformación.

Pues bien, ese es un ejercicio que cabe hacer sobre todo desde el espacio local. Precisaré entonces las preguntas iniciales: ¿es posible repensar el desarrollo desde el pensamiento local? Es claro el límite que nos impone la condición estructural, pero quizá lo es menos aquella que aparece en el orden simbólico. Clifford Geertz (1983), ha puesto de relieve -desde una hermenéutica de la cultura- esta idea del "conocimiento local" como atributo de la trama de significaciones; sin embargo es insuficiente, en la medida en que lo local no sólo es un conocimiento que se organiza y presenta como estructuración simbólica, es también inteligencia, capacidad reflexiva y analítica, o si se prefiere también es consciencia. Recurro en este punto a la problematización que propuso M. Godelier (1990). Según el antropólogo francés las relaciones 


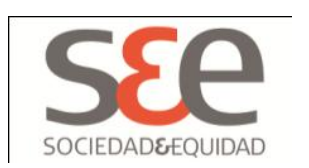

sociales de producción se presentan a sus protagonistas como condiciones dadas, como naturaleza de la vida social y económica. Exterioridad determinante. Sin embargo, en un esquema en donde las dimensiones ideaciones y materiales no están jerarquizadas en relaciones de determinación, Godelier subraya que el pensamiento tiene una parte consciente. Es esa la dimensión que permite pensar que las relaciones de producción, en apariencia opacas, no son parte de alguna naturaleza exterior sino que son producto de la propia estructuración política de la sociedad, o sea producto de unas complejas dinámicas de intersubjetividad. Es esta cualidad del pensamiento la que posibilita que los sujetos -agentes económicos- se pregunten por la posibilidad de que las cosas sean de otro modo. Es la conciencia, situada en el espacio económicocultural, la base para la transformación del orden social, para la transgresión de las identidades que discursivamente se resisten al movimiento.

\section{El desarrollo repensado desde el Archipiélago de las Guaitecas}

Mis cavilaciones se enmarcaron en una constatación que en principio no tenía nada de teórica. En realidad algo me era incomprensible desde mi sentido común, incluso más tarde, desde mi experticia antropológica. Me propuse reorientar mis preguntas desde lo que en ese entonces llamé la inteligencia local, pensamiento vivo que en una dinámica dialógica logra internarse (e internarme) en lo que rebautizaría como el punto de vista activo del nativo. Aquel que es capaz de ver y desentrañar las condiciones de su realidad pero que también imagina un futuro posible, más allá del determinismo pesimista de la expansión capitalista y también más allá del romanticismo del mundo prístino que no volverá.

De esta relación, verificable etnográficamente, creo que ha emanado un diálogo analítico sobre las condiciones de la realidad del lugar. No necesariamente lo he gatillado con mis preguntas y mis métodos, pero sí he intentado reconocer un punto de partida en esa inteligencia reflexiva y analítica localizada. En ese marco creo necesario renunciar a la omnipotencia las verdades expertas y relativizar el determinismo estructural. En la superación de esos límites estriba el germen, el espacio reflexivo desde donde emana una manera de reformular el desarrollo a partir de los atributos culturales del espacio local. La mirada político-cultural a los espacios de desarrollo alude a subjetividades del lugar, capaces de re-imaginar las condiciones de su realidad y transformarlas en proyecto colectivo.

En mis últimos trabajos de campo, influenciado por esta perspectiva, me propuse reformular sustancialmente el enfoque metodológico que tenía visualizado. Quería construir escenarios del desarrollo, testimoniados por actores locales pero sobre todo la activación de procesos analíticos en mis interlocutores. La idea era lograr una profundidad reflexiva de base cultural local, que suele ser esquiva. La clave del proceso estuvo en la aplicación de 2 grupos de discusión y 22 entrevistas semi-estructuradas, cuyos los resultados parciales fueron analizados en terreno con dos pescadores del lugar. Particularmente sugerente fue la experiencia de rediseñar el grupo de discusión e interpretarlo con Manuel, luego de su realización. En ese contexto, junto al equipo que me acompañó en terreno, pudimos acceder a una lectura endógena de los datos obtenidos. 


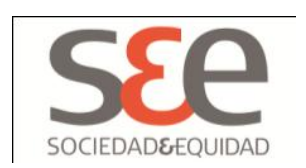

El punto de vista del nativo fue en este caso no sólo fuente de información, también fue parte del ejercicio interpretativo-analítico.

Los cuatro escenarios fueron construidos desde una matriz empírica asentada en la consciencia local, en la capacidad analítica y reflexiva de los actores del espacio pesquero artesanal. A continuación haré una síntesis de cada uno de esos escenarios, ilustrándolos con algunas citas textuales, para luego concluir con un análisis más integral. Es importante recordar que todas las conversaciones fueron instaladas a partir de mi preocupación inicial: ¿ por qué la respuesta local en Huichas y Guaitecas- frente a las consecuencias negativas de la salmonicultura parece no asumir -o entender - el conflicto? Trataba de comprender significados y sentidos identitarios que en esos espacios pesquero-artesanales suponía la gran avanzada salmonera. En el fondo, quería saber qué proyectos de base local, realizados o potenciales, se entretejían con el gran proyecto acuícola, en apariencia tan disruptivo.

Siguiendo una secuencia convencional construí los cuatro escenarios del desarrollo jerarquizados en prioridades: el histórico, el contemporáneo, el futuro realista y el futuro deseado. Los dos primeros fueron más fáciles, en parte porque la imagen del pasado emana de una oralidad que tiende a asociarlo a ciertos hitos y procesos consensuados en imaginarios comunes. Todos aluden a unos orígenes enmarcados en travesías de abuelos y antepasados que vinieron de Chiloé o Calbuco. Esas migraciones explican, en los testimonios obtenidos, las oleadas extractivistas que configuraron la historia económica local -taladores, cazadores y pescadores-, caracterizada por la dependencia hacia los empresarios que habilitaron las faenas.

La imagen del presente es aun más consensuada, hay menos lugar a la ficción. Todos somos testigos de los hechos. Por entonces había cierto pesimismo y una sensación contradictoria. Pesimismo porque era evidente que la industria estaba desplazando a la pesca artesanal y contaminando el fondo marino. Contradictoria porque aun así para la mayoría de los buzos, por diversas razones, los centros de cultivo eran laboralmente atractivos.

El día de hoy parece muy atractivo el sueldo de cuatrocientos mil pesos para los buzos... en las salmoneras, pero en la medida en que nos vayamos quedando en las salmoneras vamos a ir perdiendo espacios y vamos a ir perdiendo recursos... Cuando queramos volver al mar no vamos a tener ni espacio ni recursos a lo mejor, y los cuatrocientos mil pesos no van a subir. Van a pasar un, dos, tres años y después los cuatrocientos mil pesos no van a valer... uno puede trabajar un tiempo en las salmoneras, pero uno tiene un espíritu de pescador... esas pegas son prestadas. Uno siempre va a ser pescador ${ }^{5}$.

5 Grupo de discusión: Buzo bentónico-salmonero, Puerto Melinka, julio 2007. 


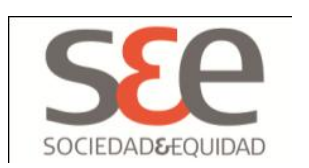

Pero la tensión era aun más evidente, si se trataba de analizar los impactos en el medioambiente: "...hubiera sido mejor conservar lo natural del litoral de Aguirre, lo natural, o sea no que llegue una salmonera y no me pueda comer un erizo que está al lado porque está contaminado" 6 . "Ese salmón tiene que morir todo, porque está totalmente enfermo. Y usted cree que las corrientes, esas cosas que andan ahí, usted cree que van a quedar en una sola parte. Y esas cosas les están afectando y aunque uno no lo crea. Al fondo marino lo está afectando"”.

Al igual que en los otros escenarios, la imagen del presente permitía observar una matriz productiva percibida en transición hacia la salmonicultura. No obstante, la situación real era bastante más equilibrada. De hecho el espacio analítico del grupo de discusión y de las entrevistas permitía ver que tras la grandilocuencia salmonera persistían diversos oficios pesqueroartesanales e incluso dinámicas de emprendimiento innovadoras sobre esa matriz tradicional.

Imaginando los escenarios del futuro

El presente, debatido y reflexionado en las instancias propuestas, sirvió de referencia para imaginar y, hasta cierto punto, modelar el futuro. El complejo escenario descrito más arriba daba lugar a la pregunta por el futuro realista. El retrato de ese futuro aparecía teñido de color salmón, tal vez de forma exagerada. La impresión era la de una industria poderosísima, imparable, próspera pero también destructiva y excluyente. Ciertamente había en ello un malestar, el que sin embargo no expresaba un movimiento de base social orientado a detener o a limitar su avance. Este era un futuro pesimista, en algún sentido era un buen futuro para otros. Coincidentemente este era y es el futuro del desarrollo convencional, pensado desde arriba.

Una síntesis de este retrato para las Guaitecas (Puerto Melinka), aparece en los siguientes testimonios. En ellos es patente la proyección hacia la salmonicultura, cuyo condicionante era la evidencia sólo relativa de la inminente crisis que se venía gestando y en consecuencia de la ralentización del proceso. Obsérvese la connotación pesimista de esta imagen del futuro, como he remarcado, al punto de invisibilizar otras prácticas y oficios de base pesquero-artesanal que han seguido siendo relevantes.

"Si en estos momentos hay trescientas, cuatrocientas concesiones acuícolas, hay el doble de eso esperando ser liberados por la CONAMA y están esperando eso. Y cada vez van llegando, llegando y llegando más. Pero el fuerte, lo más grande en la región, va a ser la salmonera” ${ }^{8}$.

“Nosotros vamos a esclavizarnos el día de mañana a las salmoneras... De la poca gente que queda en el mar, que tiene que allegarse a eso, vamos a hacerlo, a eso vamos. Nos van a limitar el mar que vamos a tener el día de mañana, ya que se están vendiendo las aguas”. ${ }^{9}$.

6 Entrevista a Lorena Taruman, pescadora artesanal de Puerto Aguirre [Islas Huichas], Coyhaique, Agosto 2007.

${ }^{7}$ Grupo de discusión: Buzo salmonero, Puerto Melinka, julio 2007.

${ }^{8}$ Entrevista a trabajadora empresa prestadora servicios, Puerto Melinka, julio 2007. 


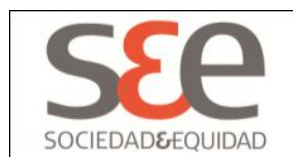

Si la acuicultura industrial era percibida con una alta probabilidad de desarrollo, al punto de transformar todo el sistema económico local, con las otras actividades no sucedía lo mismo. Con la excepción de un buzo comercial (no nativo) ninguno de los entrevistados(as) consideró en primera ni en segunda prioridad el desarrollo de alguna otra actividad. En este sentido se explica que proyecciones más optimistas al respecto, en general no sean vislumbradas desde la reflexividad local.

Sin embargo, esta proyección no es coincidente con la imagen deseada, con el futuro que se quisiera. Como se verá luego, la tendencia es bastante opuesta. Lo anterior revelaba lo problemático que ha sido (y es todavía) la expansión de la salmonicultura en la zona sur-austral. Cabe insistir en la incertidumbre que en la actualidad atraviesa todo el proyecto expansivo salmonero.

El cuarto escenario, el futuro deseado del desarrollo sur-austral, no alude una imagen exenta de realidad. Ello en tanto la pregunta siempre se formuló en un contexto de análisis y diálogo sobre las condiciones de ese entonces, de hecho en las entrevistas es la interrogante que sigue a la pregunta por las proyecciones realistas, que a su vez es una respuesta antecedida por un diagnóstico de la situación actual. Asimismo, cabe destacar que cada persona entrevistada fue seleccionada porque en el perfil sociocultural de la muestra poseía un saber práctico y/o conceptual relevante; de tal manera que es un informante clave, un experto o experta.

A modo de contraste, llama la atención que la imagen deseada muestra un escenario de "desarrollo" integral, equilibrado, desde el punto de vista del aprovechamiento de los recursos naturales y de las prácticas económicas locales. En ese nivel, existe una tensión clarísima entre ambos escenarios supuestos. Esto resulta aún más evidente al cotejarse o al ampliarse estas visiones con datos obtenidos en las otras localidades del litoral austral. Existiría una relación inversa entre la imagen realista y la deseada.

A continuación presento un cuadro que contiene testimonios que ilustran las proyecciones deseadas del desarrollo en las Islas Guaitecas.

\footnotetext{
${ }^{9}$ Grupo de discusión con buzos bentónicos y salmoneros, Puerto Melinka, julio 2007.
} 


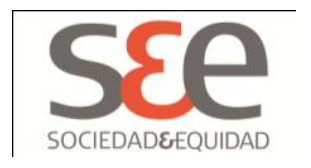

Cuadro $n^{\circ} 1$ : Escenario de futuros deseados según prioridad estructural, Islas Guaitecas

\begin{tabular}{|c|c|c|}
\hline Actividad & Referente discursivo significativo & Prioridad \\
\hline $\begin{array}{l}\text { Procesamient } \\
\text { o de recursos } \\
\text { a escala local } \\
\text { (artesanal) }\end{array}$ & $\begin{array}{l}\text { "Los pescadores tenemos que apuntar a darle otro valor a } \\
\text { nuestros productos. Hablar de menos cantidad y un mejor precio. } \\
\text { Por ejemplo a apuntar a hacer una planta procesadora de } \\
\text { productos del mar", entrevista a dirigente bentónico, Puerto } \\
\text { Melinka, junio } 2007 \text {. } \\
\text { "Y en vez de sacar un camión o una lancha con mil cajas de } \\
\text { erizos... saquemos veinte bandejas de erizo procesado, es menor } \\
\text { el volumen, pero generaste mucho más trabajo y vas a ganar } \\
\text { mucho más", entrevista a dirigente de pescadores artesanales } \\
\text { (Marcos Silva), Puerto Melinka, octubre } 2003 \text {. }\end{array}$ & 1 \\
\hline $\begin{array}{l}\text { Diversificación } \\
\text { pesquera } \\
\text { artesanal }\end{array}$ & $\begin{array}{l}\text { "Tienen la mente metida en un sólo recurso, pese a que tenemos } \\
\text { una variedad enorme de recursos. [La gente] va a tener hoy en } \\
\text { día que cambiar de mentalidad, variar más en sus extracciones y } \\
\text { no abocarse solamente a una sola extracción", entrevista a } \\
\text { Genaro Barría, Puerto Melinka, octubre } 2003 \text {. }\end{array}$ & 1 \\
\hline $\begin{array}{ll}\text { Acuicultura a } \\
\text { escala } \\
\text { artesanal }\end{array}$ & $\begin{array}{l}\text { "Nosotros tenemos un sueño, es un sueño que no todos los } \\
\text { pescadores lo tienen: sembrar productos aquí, por ejemplo } \\
\text { trabajar con el chorito...", entrevista asocio de sindicato de } \\
\text { pescadores artesanales, Puerto Melinka, julio } 2007 \text {. } \\
\text { "La idea es formar un grupo de acuicultores dentro de la } \\
\text { institución y partir con cuatro, cinco y los otros que vean que } \\
\text { funciona", entrevista a Genaro Barría, Puerto Melinka, octubre } \\
2003 \text {. }\end{array}$ & 2 \\
\hline $\begin{array}{l}\text { Salmonicultur } \\
\text { a }\end{array}$ & $\begin{array}{l}\text { "Si tú pones una planta procesadora [de salmones] acá, significa } \\
\text { que va a haber más movimiento, va a haber más ingreso... Las } \\
\text { empresas producirían su mismo salmón aquí en Melinka. Y a lo } \\
\text { mejor a futuro uno quiere eso, o sea que el producto sea } \\
\text { procesado aquí...", entrevista trabajadora empresa de servicios } \\
\text { acuícolas, Puerto Melinka, julio } 2007 \text {. }\end{array}$ & 2 \\
\hline $\begin{array}{l}\text { Desarrollo } \\
\text { turístico }\end{array}$ & $\begin{array}{l}\text { "Hemos conversado harto con los muchachos estos, de la } \\
\text { Universidad Austral para desarrollar eso; incluso ellos ofrecieron } \\
\text { un par de personas que quieren llevar a Nueva Zelanda... para ir a } \\
\text { ver cómo están trabajando los artesanales el tema del turismo, } \\
\text { cómo lo han desarrollado, aprender lo bueno y lo malo de ellos", }\end{array}$ & 3 \\
\hline
\end{tabular}




\section{SEe}

\begin{tabular}{|l|l|l|}
\hline & $\begin{array}{l}\text { entrevista a dirigente de sindicato de pescadores artesanales, } \\
\text { Puerto Melinka, junio 2007. }\end{array}$ & \\
\hline $\begin{array}{l}\text { Desarrollo } \\
\text { bentónico }\end{array}$ & $\begin{array}{l}\text { "Uno puede trabajar un tiempo en las salmoneras pero uno tiene } \\
\text { un espíritu, un espíritu de pescador...esas [oficios] pegas son } \\
\text { prestadas. Uno siempre va a ser pescador," Grupo de discusión, } \\
\text { Puerto Melinka, julio 2007. } \\
\text { "Hay que resguardar lo que [queda], no pongan más salmoneras } \\
\text { en donde se trabaja, nada más, y protegerlo y listo... porque esa } \\
\text { es la única, la única solución que podemos tener al mar", Grupo } \\
\text { de discusión, Puerto Melinka, julio 2007. }\end{array}$ & \\
\hline
\end{tabular}

Creado por el autor.

Las proyecciones deseadas en Guaitecas revelan una mirada crítica a la expansión desregulada de la salmonicultura, en esos términos se visualiza como una amenaza más que como oportunidad. 0 tal vez como una figura ambivalente: una amenaza que además supone una oportunidad, condición doble-vinculante (culturalmente esquizofrénica) que la hace más compleja en términos de formular alternativas reales a la misma.

Pero las limitaciones también son percibidas por los buzos mariscadores y por la comunidad en general. Si bien la imagen deseada quiere recobrar la centralidad de la práctica bentónica, esta proyección no deja de reconocer los factores condicionantes. En especial la contaminación. Incluso puede hablarse de una voluntad cultural por reproducir, aunque no desde una claridad estratégica definida, la condición de pescador artesanal.

"Tenemos que seguir siendo pescadores.... Yo siempre he comentado que tengo, cinco hijos. Como decía..., hoy día yo no les puedo dar estudios a todos, uno de tantos va a fallar. Él tiene que ser pescador. Claro, si es la realidad. Yo puedo sacar, tres, cuatro, puedo también tirar a... que tengan un puestito también, pueden llegar, pero uno va a fallar y ese tiene que vivir del mar"10.

Es ciertamente una declaración a todas luces representativa del sentimiento de la comunidad bentónica: la comunidad perdida. Al respecto, remirando la historia o las historias económicas de estas latitudes, cabe preguntarse si alguna vez, en algo más de un siglo, hubo un uso integral de los recursos naturales, aun sin mediar un proyecto económico-cultural deliberado. En ese marco subrayo la proyección hacia el procesamiento de los recursos extraídos por la flota bentónica local. Diversos testimonios, en Guaitecas y Huichas, describen economías locales que no se articulan en prácticas extractivistas, ni tampoco en una "industrialización" exógena transnacional. En ese enfoque proyectivo la micro-industrialización potencial de las economías bentónicas

10 Buzo bentónico salmonero, Puerto Melinka, Julio 2007 (Grupo de discusión). 


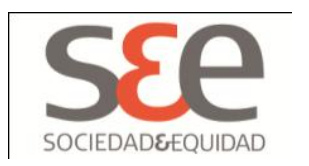

tradicionales, es una alternativa que no sólo se fundamenta en un pasado que sigue marginalmente vivo -incluso en una condición práctica de capital acumulado-, sino especialmente en lo que llamaré un proyecto económico alternativo, autónomo y estratégico. Un proyecto económico imaginado, y en ese sentido político-cultural, con un fuerte componente de sustentabilidad. $\mathrm{O}$ tal vez deba entenderse como una ruptura subjetiva con la condición extractivista que no permite enfrentar la proyección industrial foránea.

\section{Conclusiones}

Inmersas en los escenarios del desarrollo modernizador no hay una sola estrategia, tampoco una diversidad anclada en la homogeneidad cultural. En esta lectura las respuestas de las subjetividades locales, en el marco de sus dinamismos identitarios, es en primer término una problemática conceptual-metodológica. Por ejemplo la resistencia, la reformulación creativa o la transformación deliberada del orden social, pueden ser estrategias según cada caso, no obstante hay una condición insoslayable: para conocer esas estrategias es necesario estar allí, etnográficamente allí. Considerando esta observación destaquemos que en las costas suraustrales ha habido diferentes posiciones y respuestas frente a los procesos de "desarrollo", impulsados tanto desde el Estado como desde las empresas privadas. Algunas de estas respuestas han sido expresadas en forma discursiva y otras por la vía de concreciones prácticas. Por ejemplo, en el discurso pesquero artesanal, las visiones sobre la expansión salmonera son muy críticas, no obstante como he señalado más arriba esa posición (discursiva y hasta cierto punto contemplativa) no alcanza a constituir una plataforma política consistente.

Una respuesta bien evidente respecto de la salmonicultura, es el aprovechamiento transversal por parte de unas y otras comunidades en tanto oportunidad de empleo. Sin embargo también aquí se pone en evidencia un contraste llamativo: muchos de quienes se han empleado en los centros de cultivo, pero al mismo tiempo poseen estatus de pescadores artesanales, reniegan de esas ocupaciones aduciendo transitoriedad. En mi percepción, este sentimiento interpretaba a mediados de 2007 a las personas que compartieron conmigo en las islas Guaitecas. Asimismo habría que remarcar la adaptación de algunos servicios locales a la industria, incluso creando algunos nuevos. Por ejemplo el acondicionamiento de embarcaciones para transportar trabajadores o la instalación de comercios locales -desde hospederías a ciber-cafés- con el fin de satisfacer demandas de los nuevos vecinos. Sin ser necesariamente contradictorio, lo cierto es que estos procesos se parecen mucho más a las adaptaciones exitosas o inteligentes que a la desestructuración de la economía local frente al capitalismo perverso.

Pero las respuestas más interesantes y potencialmente más sugerentes están todavía formuladas de manera embrionaria, o bien como ideas, es decir, como proyectos económicos de base local. $\mathrm{A}$ modo de síntesis destacaría tres: el procesamiento de recursos bentónicos, la comercialización y la acuicultura artesanal. En los tres casos existen antecedentes, experiencias previas, algunas fracasadas, otras más exitosas; no obstante en todos los casos el punto de partida tiene una doble potencia: por una parte esa experiencia previa, que entre otras cosas provee la anticipación de contextos problemáticos, y por otra una potencia imaginativa. Esto último parece muy 


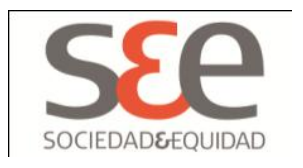

coincidente con el planteamiento de Arjun Appadurai, en relación al lugar secundario que ha tenido la variable "imaginación" en la teoría antropológica y en particular en la discusión sobre cultura. Sostengo que las principales respuestas frente a las conflictivas avanzadas del capital y las empresas transnacionales, residen en "el trabajo de la imaginación".

La base de lo posible, entendido como proyecto cultural o político cultural, encuentra su sustancia en la capacidad dialógica y reflexiva del campo del desarrollo en las costas sur-australes. Esto supone admitir que las subjetividades desplegadas en ese espacio comprenden capacidades imaginativas, auto-reflexivas, comprensivas y de acción práctica deliberada, y que a partir de esas capacidades se construyen y se están construyendo espacios económicos alternativos. Pero no en el sentido excluyente o sustitutivo, sino en el sentido del enriquecimiento, de la reelaboración o de la contextualización de aquello que en principio podría parecer ajeno. 


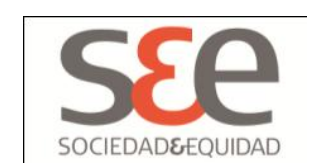

\section{Referencias Bibliográficas}

Appadurai, Arjun (2001) La modernidad desbordada. Montevideo: FCE-TRILCE.

Barkin, David y Mara, Rosas (2006) ¿Es posible un modelo alterno de acumulación? Unapropuesta para la Nueva Ruralidad. En Polis, Revista de la Universidad Bolivariana. Vol. 5 Num. 13, pp. 361-371. Disponible desde internet en formato HTML: en $<$ http://www.revistapolis.cl/13/ind13.htm>.

Buschmann, Alejandro y Fortt, Antonia (2005) Efectos ambientales de la acuicultura intensiva y alternativas para un desarrollo sustentable. Revista Ambiente y Desarrollo, 21: 3, pp. 58-64. Santiago de Chile: Centro de Investigación y Planificación del Medio Ambiente

Claude, Marcel y Oporto, Jorge (2000). La Ineficiencia de la Salmonicultura en Chile, Aspectos Sociales, Económicos y Ambientales (Publicación interna). Santiago: Terram Publicaciones.

Clifford, James (1997) Itinerarios transculturales. Barcelona: Gedisa.

CORFO (2002) Identificación y Análisis de oportunidades de inversión para la Región de Aysén, Chile. Coyhaique-Chile: Corporación de Fomento de la Producción. Agencia de Atracción y Promoción de Inversiones TODO CHILE.

Doren, Daniela y Gabella, Juan Pablo (2001) Salmonicultura en Chile: desarrollo, proyecciones e impacto. Santiago de Chile: Terram Publicaciones.

Durán, Gonzalo, Kremerman, Marco y Martín Pascual (2007) Río dulce. Un amargo encuentro con la maquila., $\mathrm{N}^{\circ} 4$. Ancud Chiloé.

Escobar, Arturo (1999) El final del salvaje. Cultura, naturaleza y política en la antropología contemporánea. Bogotá: ICANH / CEREC.

(1997) Antropología y desarrollo, Revista Internacional de Ciencias Sociales, no 154, Diciembre 1997, UNESCO. Disponible desde internet en formato HTML: en www.unesco.org/issj/rics154.html

Esteva, Gustavo (2000) Desarrollo. En Viola, A. (Comp.) Antropología del desarrollo, Teorías y estudios etnográficos en América Latina. Barcelona: Paidós.

García Canclini, Néstor (1990) Culturas Híbridas, Estrategias para entrar y salir de la modernidad. México, D. F: Grijalbo.

Geertz, Clifford (1983) Conocimiento local. Barcelona: Paidós.

Goddelier, Maurice (1990) Lo ideal y lo material. Madrid: Taurus. 


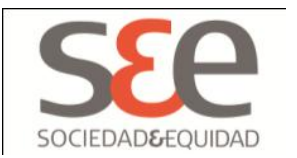

Grueso, Libia (2005) Representaciones y relaciones en la construcción del proyecto político y cultural del Proceso de Comunidades Negras en el contexto del conflicto armado en la región del Pacífico Sur colombiano. En Daniel Mato (Coord.) Políticas de economía, ambiente y sociedad en tiempos de globalización (pp. 53-70.). Caracas: Facultad de Ciencias Económicas y Sociales, Universidad Central de Venezuela.

Kremerman, Marco (2005) En la ruta del trabajo decente: Análisis de los sectores Samonicultura, Call center y Agroexportación. Fundación Terram, Serie Registro de Problemas Públicos $\mathrm{n}^{\circ} 20$, Santiago.

Pizarro, Rodrigo y Zolezzi, Cristóbal (2003) Impactos ambientales del Escape de Salmónidos, En: Análisis de Políticas Públicas, № 22, Terram Publicaciones, Santiago de Chile.

Rabinow, Paul (1992) Reflexiones sobre un trabajo de campo en Marruecos. Madrid: JUCAR.

Sahlins, Marshall (1988) Islas de historia: la muerte del capitán Cook, metáfora, antropología e historia. Barcelona: Gedisa.

Viola, Andreu (2000) Antropología del desarrollo, Teorías y estudios etnográficos en América Latina. Barcelona: Paidós. 


\section{sfe \\ somenow}

Cuadro $n^{\circ} 1$ : Escenario de futuros deseados según prioridad estructural, Islas Guaitecas

\begin{tabular}{|c|c|c|}
\hline Actividad & Referente discursivo significativo & Prioridad \\
\hline $\begin{array}{l}\text { Procesamient } \\
\text { o de recursos } \\
\text { a escala local } \\
\text { (artesanal) }\end{array}$ & $\begin{array}{l}\text { "Los pescadores tenemos que apuntar a darle otro valor a } \\
\text { nuestros productos. Hablar de menos cantidad y un mejor precio. } \\
\text { Por ejemplo a apuntar a hacer una planta procesadora de } \\
\text { productos del mar", entrevista a dirigente bentónico, Puerto } \\
\text { Melinka, junio } 2007 \text {. } \\
\text { "Y en vez de sacar un camión o una lancha con mil cajas de } \\
\text { erizos... saquemos veinte bandejas de erizo procesado, es menor } \\
\text { el volumen, pero generaste mucho más trabajo y vas a ganar } \\
\text { mucho más", entrevista a dirigente de pescadores artesanales } \\
\text { (Marcos Silva), Puerto Melinka, octubre } 2003 \text {. }\end{array}$ & 1 \\
\hline $\begin{array}{l}\text { Diversificación } \\
\text { pesquera } \\
\text { artesanal }\end{array}$ & $\begin{array}{l}\text { "Tienen la mente metida en un sólo recurso, pese a que tenemos } \\
\text { una variedad enorme de recursos. [La gente] va a tener hoy en } \\
\text { día que cambiar de mentalidad, variar más en sus extracciones y } \\
\text { no abocarse solamente a una sola extracción", entrevista a } \\
\text { Genaro Barría, Puerto Melinka, octubre } 2003 \text {. }\end{array}$ & 1 \\
\hline $\begin{array}{l}\text { Acuicultura a } \\
\text { escala } \\
\text { artesanal }\end{array}$ & $\begin{array}{l}\text { "Nosotros tenemos un sueño, es un sueño que no todos los } \\
\text { pescadores lo tienen: sembrar productos aquí, por ejemplo } \\
\text { trabajar con el chorito...", entrevista asocio de sindicato de } \\
\text { pescadores artesanales, Puerto Melinka, julio } 2007 \text {. } \\
\text { "La idea es formar un grupo de acuicultores dentro de la } \\
\text { institución y partir con cuatro, cinco y los otros que vean que } \\
\text { funciona", entrevista a Genaro Barría, Puerto Melinka, octubre } \\
2003 \text {. }\end{array}$ & 2 \\
\hline $\begin{array}{l}\text { Salmonicultur } \\
\text { a }\end{array}$ & $\begin{array}{l}\text { "Si tú pones una planta procesadora [de salmones] acá, significa } \\
\text { que va a haber más movimiento, va a haber más ingreso... Las } \\
\text { empresas producirían su mismo salmón aquí en Melinka. Y a lo } \\
\text { mejor a futuro uno quiere eso, o sea que el producto sea } \\
\text { procesado aquí...", entrevista trabajadora empresa de servicios } \\
\text { acuícolas, Puerto Melinka, julio } 2007 \text {. }\end{array}$ & 2 \\
\hline $\begin{array}{l}\text { Desarrollo } \\
\text { turístico }\end{array}$ & $\begin{array}{l}\text { "Hemos conversado harto con los muchachos estos, de la } \\
\text { Universidad Austral para desarrollar eso; incluso ellos ofrecieron } \\
\text { un par de personas que quieren llevar a Nueva Zelanda... para ir a }\end{array}$ & 3 \\
\hline
\end{tabular}




\section{sfe \\ SOCIEDADEEQUIDAD}

\begin{tabular}{|l|l|l|}
\hline & $\begin{array}{l}\text { ver cómo están trabajando los artesanales el tema del turismo, } \\
\text { cómo lo han desarrollado, aprender lo bueno y lo malo de ellos", } \\
\text { entrevista a dirigente de sindicato de pescadores artesanales, } \\
\text { Puerto Melinka, junio 2007. }\end{array}$ & \\
\hline $\begin{array}{l}\text { Desarrollo } \\
\text { bentónico }\end{array}$ & $\begin{array}{l}\text { "Uno puede trabajar un tiempo en las salmoneras pero uno tiene } \\
\text { un espíritu, un espíritu de pescador...esas [oficios] pegas son } \\
\text { prestadas. Uno siempre va a ser pescador," Grupo de discusión, } \\
\text { Puerto Melinka, julio 2007. } \\
\text { "Hay que resguardar lo que [queda], no pongan más salmoneras } \\
\text { en donde se trabaja, nada más, y protegerlo y listo... porque esa } \\
\text { es la única, la única solución que podemos tener al mar", Grupo } \\
\text { de discusión, Puerto Melinka, julio 2007. }\end{array}$ & 1 \\
\hline
\end{tabular}

Creado por el autor. 